\title{
Oxidative and Phagocytic Functions of Macrophages during Infections Induced in Mice by Mycobacterium intracellulare and Listeria monocytogenes
}

\author{
By HAJIME SAITO, ${ }^{*}$ HARUAKI TOMIOKA, ${ }^{1}$ YOSHITAKA YAMADA ${ }^{1,2}$ \\ AND JOJI JIDOI² \\ Departments of Microbiology and Immunology ${ }^{1}$ and Dermatology ${ }^{2}$, Shimane Medical Unicersity, \\ Izumo 693, Japan
}

(Received 10 September 1985 ; revised 18 November 1985)

\begin{abstract}
The oxidative metabolism (chemiluminescence and $\mathrm{H}_{2} \mathrm{O}_{2}$ release) and phagocytic activity of mouse peritoneal macrophages during chronic infections induced by Mycobacterium intracellulare and more acute infections due to Listeria monocytogenes were studied. In $M$. intracellulare infections, macrophage chemiluminescence in response to phorbol myristate acetate (PMA) was greatest at around 2 weeks, with a 1 week lag phase after infection, while the PMA-triggered $\mathrm{H}_{2} \mathrm{O}_{2}$ release was markedly enhanced even $1 \mathrm{~d}$ after challenge, and remained high thereafter for up to 10 weeks. The pattern of changes in the phagocytic activity of host macrophages in response to latex beads during this infection resembled the pattern seen with macrophage $\mathrm{H}_{2} \mathrm{O}_{2}$ release. In the L. monocytogenes infections, the PMA-triggered chemiluminescence of the host macrophages increased $4 \mathrm{~d}$ (in a sublethal infection) and $2 \mathrm{~d}$ (in a lethal infection) after bacterial challenge, whereas the PMA-triggered $\mathrm{H}_{2} \mathrm{O}_{2}$ release was markedly enhanced as early as $1 \mathrm{~d}$ after infection and the elevated level persisted until either the bacteria were eliminated or the animals died. The patterns of changes in phagocytic activity of the host macrophages during $L$. monocytogenes infection at sublethal and lethal doses differed. In the former, phagocytosis was most active in the early phase of infection, with a peak around day 2 , followed by a rapid decrease; in the latter, the phagocytic ability increased more slowly, and remained elevated until the animals died. The results suggest that the macrophages induced by $M$. intracellulare are in a more activated state than are those induced by L. monocytogenes.
\end{abstract}

\section{INTRODUCTION}

Certain macrophage cell functions are modulated during bacterial, fungal and protozoal infections. Stimulation and/or activation of the host macrophages, based on their phagocytic or antimicrobial activities, occur in cases of infection due to Brucella abortus (Cheers \& Pagram, 1979), Mycohacterium tuberculosis (North, 1974; King et al., 1975), Blastomyces dermatitidis (Brummer et al., 1980) and Trypanosoma cruzi (Nogueira et al., 1977). In contrast, suppression of some macrophage functions, such as pinocytic activity, chemotactic response and bactericidal activity, are seen in BCG infections (Wing, 1981) and Toxoplasma infections (Jones \& Len, 1976) in mice, and in active pulmonary tuberculosis in humans (Campbell, 1979). There are few reports dealing with detailed changes in macrophage function during infection, i.e. from the onset of infection until recovery or death of the animal host. Here, we report changes in macrophage oxygen metabolism (chemiluminescence and $\mathrm{H}_{2} \mathrm{O}_{2}$ release) and phagocytic ability during infections induced in mice by the intracellular parasites Listeria monocytogenes (acute infection) and Mycobacterium intracellulare (chronic infection).

Ahhreriations: PMA, phorbol myristate acetate; HBSS. Hanks'balanced salt solution: PBS, phosphate-buffered saline; MEM. Fagle's minimal essential medium: PC, peritoneal cells: PMNL, polymorphonuclear leucocytes: FBS, foetal bovine serum; p.i., post-infection. 


\section{METHODS}

Animals. Female ddY strain mice (6 to 8 weeks) were purchased from the Shizuoka Union for Experimental Animals, Shizuoka, Japan.

Experimental infections. Listeria monocytogenes EGD (obtained from K. Takeya, Kyushu University, Fukuoka, Japan) and Mycobacterium intracellulare 31F093 TD (obtained from F. Kuse, Kyoto University, Kyoto, Japan) were cultured in tryptosoy broth (Eiken Chemical Co.) at $37^{\circ} \mathrm{C}$ for $18 \mathrm{~h}$ and in Dubos Tween-albumin medium (Eiken) at $37^{\circ} \mathrm{C}$ for $7 \mathrm{~d}$, respectively. Bacteria were harvested by centrifugation at $2000 \mathrm{~g}$ for $15 \mathrm{~min}$, washed twice with phosphate-buffered ( $\mathrm{pH} \mathrm{7.0)} \mathrm{saline} \mathrm{(PBS)} \mathrm{and} \mathrm{finally} \mathrm{suspended} \mathrm{in} \mathrm{PBS.} \mathrm{The} \mathrm{bacterial} \mathrm{suspension} \mathrm{was}$ injected intraperitoneally into mice (see figure legends for details). At various intervals, the number of organisms in the liver, spleen and lungs of the infected animals was determined by plating tenfold serial dilutions of the tissue homogenates on tryptosoy agar and Middlebrook $7 \mathrm{H} 10$ agar (Difco) for L. monocytogenes and M. intracellulare, respectively.

Assay for chemiluminescence of host peritoneal cells. The peritoneal cells (PC) of the host mice, with or without infection, were harvested with Eagle's minimal essential medium (MEM) (Nissui Pharmaceutical Co.) containing 100 units penicillin $\mathrm{G} \mathrm{ml}^{-1}, 100 \mu \mathrm{g}$ streptomycin $\mathrm{ml}^{-1}$, and 5 or 10 units heparin $\mathrm{ml}^{-1}$. The PC were treated with distilled water for $15 \mathrm{~s}$ to lyse any contaminating erythrocytes, washed twice with PBS, and suspended in Hanks' balanced salt solution (HBSS). For measurement of chemiluminescence, the PC $\left(10^{\circ}\right.$ cells in $\left.0.9 \mathrm{ml}\right)$ were added to a glass vial ( $12 \mathrm{~mm}$ diameter, $15 \mathrm{~mm}$ length) with $0 \cdot 1 \mathrm{ml} 10^{-3} \mathrm{M}$-luminol and the basal light emission was recorded using a Lumicounter ATP-237 (Toyo Kagaku Ind.) over $10 \mathrm{~s}$ periods at $37^{\circ} \mathrm{C}$. To this preparation was added either between 1 and $100 \mathrm{ng}$ phorbol myristate acetate (PMA) (Sigma) in $10 \mu \mathrm{l}$ dimethylsulphoxide, or $100 \mu \mathrm{g}$ latex beads $(0.8 \mu \mathrm{m}$; Sigma $)$ in $10 \mu \mathrm{l}$ HBSS, and light emission was recorded for $10 \mathrm{~s}$ periods at intervals for up to $10 \mathrm{~min}$ after addition.

Assay for release of $\mathrm{H}_{2} \mathrm{O}_{2}$ from macrophages. $\mathrm{PC}$ were prepared from normal and infected mice, as described above, except that any contaminating erythrocytes were lysed by treatment with $0.83 \%(\mathrm{v} / \mathrm{v}) \mathrm{NH}_{4} \mathrm{Cl}$ in $0.17 \mathrm{M}^{-}$ Tris/ $\mathrm{HCl}$ buffer ( $\mathrm{pH} \mathrm{7.6)}$ and the subsequent washing of the $\mathrm{PC}$ was done with PBS supplemented with $1 \%$ foetal bovine serum (FBS) (M. A. Bioproducts). The resultant PC were suspended in MEM supplemented with $10 \%$ $(\mathrm{v} / \mathrm{v}) \mathrm{FBS}, 100$ units penicillin $\mathrm{G} \mathrm{ml}^{-1}$, and $100 \mu \mathrm{g}$ streptomycin $\mathrm{ml}^{-1}$. To prepare macrophage monolayers, $4 \mathrm{ml}$ of the cell suspension $\left(2 \times 10^{6}\right.$ cells) was allowed to settle onto the surface of a $50 \mathrm{~mm}$ plastic culture dish (Nunc). After incubation at $37{ }^{\circ} \mathrm{C}$ for $2 \mathrm{~h}$ in a $\mathrm{CO}_{2}$ incubator $\left(5 \% \mathrm{CO}_{2} / 95 \%\right.$ humidified air $)$, the dish was thoroughly rinsed with PBS. Macrophage $\mathrm{H}_{2} \mathrm{O}_{2}$ release was measured using the resultant macrophage monolayer culture $\left(6.8 \times 10^{5}\right.$ to $1.3 \times 10^{6}$ cells per dish), as described by Tomioka \& Saito (1980). Briefly, the macrophage monolayer was overlaid with $2.4 \mathrm{ml}$ HBSS containing $0 \cdot 1 \%(\mathrm{w} / \mathrm{v})$ glucose, horseradish peroxidase $\left(50 \mu \mathrm{g} \mathrm{ml}^{-1}\right.$; type II ; Sigma), and $5 \mathrm{nmol}$ scopoletin (reduced type; Sigma), and the dish incubated in the presence ( 1 to $100 \mathrm{ng} \mathrm{ml}^{-1}$ ) or absence of PMA at $37^{\circ} \mathrm{C}$ for $20 \mathrm{~min}$ in a $\mathrm{CO}_{2}$ incubator. The medium was removed and measured for its fluorescence at $460 \mathrm{~nm}$ by setting the excitation light at $350 \mathrm{~nm}$ in an Aminco Bowman TM spectrophotofluorometer. Macrophage $\mathrm{H}_{2} \mathrm{O}_{2}$ release was expressed as pmol $\min ^{-1}$ per $10^{\circ}$ adhered cells.

Macrophage phagocytosis. Phagocytosis of latex particles by macrophages was measured according to Tomioka \& Saito (1980), with minor modifications. Briefly, the macrophage monolayer, prepared as described above, was overlaid with $2 \mathrm{ml} \mathrm{10 \%}$ FBS-MEM containing $100 \mu \mathrm{g}$ latex beads $(0.8 \mu \mathrm{m}) \mathrm{ml}^{-1}$, with or without addition of $10 \mathrm{ng}$ PMA in $10 \mu \mathrm{l}$ dimethylsulphoxide. After $20 \mathrm{~min}$ incubation in a $\mathrm{CO}_{2}$ incubator at $37^{\circ} \mathrm{C}$, the macrophage monolayer was rinsed three times with PBS, fixed with methanol and stained with Giemsa's solution, and the number of latex beads ingested per macrophage was counted microscopically.

\section{RESULTS}

\section{Changes in oxidative metabolism of macrophages during $M$. intracellulare infection}

Fig. 1 shows changes in the chemiluminescence of the host PC in response to PMA-triggering or to latex phagocytosis. The infection was chronic and there was a very slow decrease in the number of viable organisms in the spleen during the 6 weeks post-infection (p.i.) (Fig. $1 d$ ). In this infection, the chemiluminescence of the PC triggered by PMA showed a transient increase at $1 \mathrm{~d}$ p.i. (Fig. 1 a). This may have been attributable to the accumulation of polymorphonuclear leucocytes (PMNL) in the peritoneal cavity due to acute inflammation elicited by the bacterial inoculum (Fig. 1b,c). PMNL have a high ability to generate active oxygen, of which ${ }^{\circ} \mathrm{OH}$ and/or ${ }^{\prime} \mathrm{O}_{2}$ are thought to cause light emission (Johnston, 1978), as in the case of activated macrophages (Nathan \& Root, 1977). A marked increase in the PMA-elicited chemiluminescence of the PC was noted around 2 weeks p.i. This was probably due to activation of the host peritoneal macrophages, because the proportion of PMNL in the PC at this stage of the infection was not high enough to produce such an increase (the PC at $1 \mathrm{~d}$ p.i. consisted of $5 \%$ PMNL and showed 


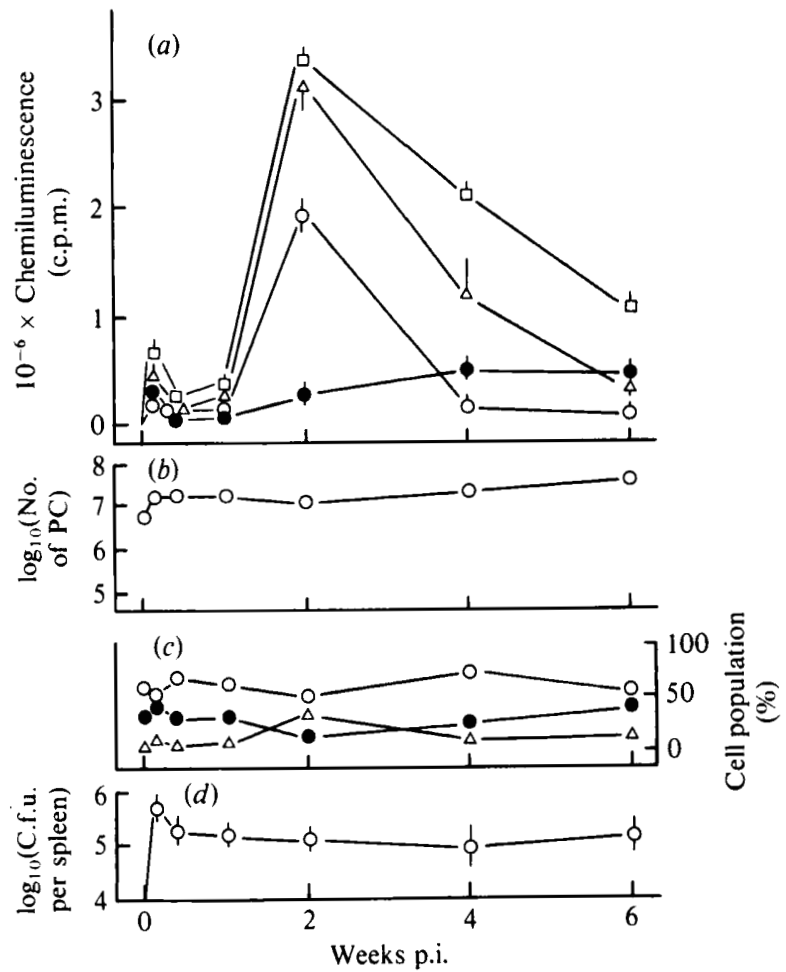

Fig. 1. Changes in PMA-triggered and phagocytosis-associated chemiluminescence of host PC after intraperitoneal infection with $M$. intracellulare $\left(1 \times 10^{6} \mathrm{c}\right.$.f.u. per mouse). PC were harvested from five mice and pooled. A separate cell culture was prepared for chemiluminescence. $(a)$ Chemiluminescence triggered by $1(O), 10(\triangle)$, and $100(\square) \mathrm{ng} \mathrm{PMA} \mathrm{ml}^{-1}$ or elicited by phagocytosis of latex beads $(100 \mu \mathrm{g}$ $\left.\mathrm{ml}^{-1}\right)(\bigcirc)$ The results are means \pm range; $n=2$. (b) Number of $\mathrm{PC}$ (mean; $n=5$ ). (c) Cell population in PC: $O$, macrophages; $\triangle$, PMNL: lymphocytes. (d) Number of c.f.u. of organisms in the spleen (means \pm range, $n=5$ ).
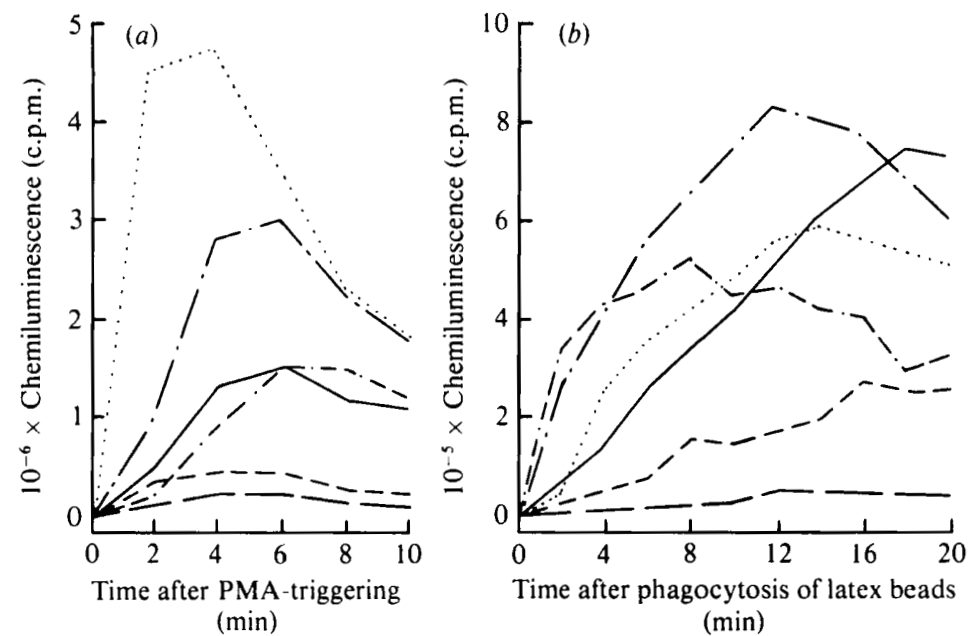

Fig. 2. Time-course of light emission from host $\mathrm{PC}$ after infection with $\boldsymbol{M}$. intracellulare. (a) Chemiluminescence triggered with PMA at $100 \mathrm{ng} \mathrm{ml}^{-1}$; (b) chemiluminescence associated with phagocytosis of latex beads. - Chemiluminescence at $1 \mathrm{~d} ;-\cdots, 3 \mathrm{~d} ;-\cdots, 7 \mathrm{~d} ; \cdots \cdots, 2$ weeks; _.- 4 weeks; -...., 6 weeks p.i. Other details are as described in Fig. 1. 


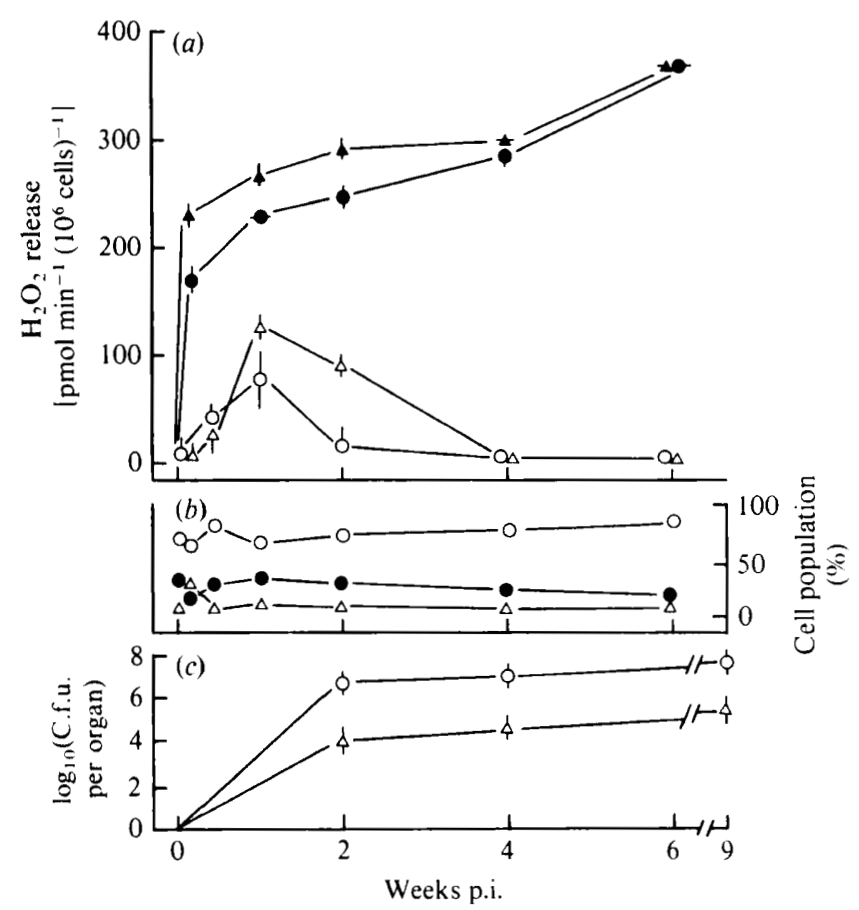

Fig. 3. Changes in PMA-triggered $\mathrm{H}_{2} \mathrm{O}_{2}$ release from host macrophages after intraperitoneal infection with $M$. intracellulare $\left(1 \times 10^{6}\right.$ c.f.u. per mouse) $(a) \mathrm{H}_{2} \mathrm{O}$, release without $\mathrm{PMA}(\mathrm{O})$ and in response to $1(\triangle), 10(\bigcirc), 100(\Delta) \mathrm{ng} \mathrm{PMA} \mathrm{m} \mathrm{I}^{-1}$. (b) Cell population in the macrophage monolayer culture tested: $O$, macrophages: $\triangle$, PMNL: lymphocytes. $(c)$ Number of c.f.u. of organisms in the spleen $(O)$ and lung $(\triangle)$. The results are means \pm range (in $a$ and $c$ ); $n=2$ in $(a)$ and 5 in $(c)$; a horizontal bar indicates that the results were identical.

much less chemiluminescence than did the PC at 2 to 6 weeks p.i. with a similar proportion of PMNL). The PMA-triggered chemiluminescence of the PC during 2 to 6 weeks p.i. was dosedependent. It is noteworthy that the chemiluminescence of the PC in response to phagocytosis of latex beads (Fig. 1 $a$ ) gradually increased from 2 weeks p.i. until a peak was reached at 4 to 6 weeks p.i.

Fig. 2 shows the time course of PMA-triggered and phagocytosis-associated chemiluminescence of the PC used in the experiment shown in Fig. 1. The peak value of PMA-triggered chemiluminescence of a given PC preparation correlated well with the cumulative intensity of light emission. However, such a clear relationship was not noted in the case of phagocytosisassociated chemiluminescence.

Fig. 3 shows the changes in the spontaneous and PMA-triggered $\mathrm{H}_{2} \mathrm{O}_{2}$-releasing ability of macrophages during $M$. intracellulare infection (a separate experiment from that presented in Figs 1 and 2). In this case, the $\mathrm{H}_{2} \mathrm{O}_{2}$-releasing ability of the macrophages in response to triggering by PMA at 10 and $100 \mathrm{ng} \mathrm{ml}^{-1}$ was elevated as early as $I \mathrm{~d}$ p.i. This enhanced state continued for at least 6 weeks. Also, macrophage $\mathrm{H}_{2} \mathrm{O}_{2}$ release in response to $1 \mathrm{ng} \mathrm{ml}^{-1}$ PMA and without PMA was significantly enhanced around I to 2 weeks p.i. The increase in the high dose PMA-triggered $\mathrm{H}_{2} \mathrm{O}_{2}$ release from 'macrophages' obtained at $1 \mathrm{~d}$ p.i. may have been partly attributable to a high rate of contamination of PMNL in the macrophage monolayer culture (Fig. $3 b$ ).

Changes in the oxidative metabolism of host macrophages during L. monocytogenes infection

Fig. 4 shows the changes in PMA-triggered and phagocytosis-associated chemiluminescence of PC from mice infected with sublethal and lethal doses of L. monocytogenes. In the sublethal infection a relatively small number of the organisms were retained in the host liver for 1 to $7 \mathrm{~d}$ 


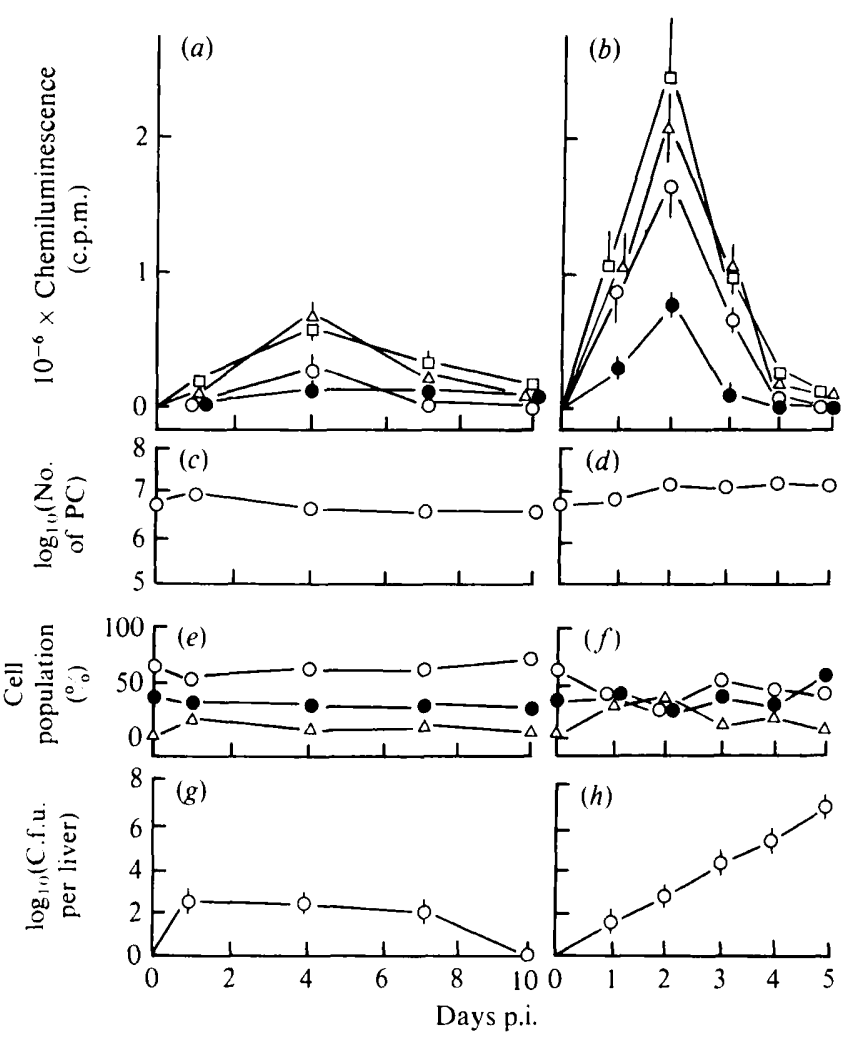

Fig. 4. Changes in PMA-triggered and phagocytosis-associated chemiluminescence of host PC after intraperitoneal infection with $L$. monocitogenes at doses of $1.5 \times 10^{6}$ (sublethal) $(a, c, e, g)$ and $2.5 \times 10^{7}$ (lethal) $(b, d, f, h)$ organisms per mouse. $(a, b)$ Chemiluminescence; $(c, d)$ number of $\mathrm{PC} ;(e, f)$ cell population in PC: $\bigcirc$. macrophages: $\triangle$, PMNL; lymphocytes; $(g, h)$ number of c.f.u. of organisms in the liver. In the lethal infection $70^{\circ}$ of the mice survived at $5 \mathrm{~d}$ p.i. See Fig. 1 for other details.

p.i. and were thereafter eliminated (Fig. $4 \mathrm{~g}$ ), while in case of the lethal infection, the organisms in the liver continued to increase until the death of the animals $5 \mathrm{~d}$ p.i. (Fig. $4 h$ ). In the sublethal infection (Fig. $4 a, c, e, g$ ), a slight enhancement in PMA-triggered chemiluminescence, mainly due to macrophages (Fig. $4 e$ ), was observed around 4 d p.i. (Fig. $4 a$ ). It is noteworthy that there was no elevation of PMA-triggered chemiluminescence $1 \mathrm{~d}$ p.i., in spite of a significant increase in the ratio of PMNL in the PC preparation (Fig. $4 a, e$ ). In the lethal infection (Fig. $4 b, d, f, h$ ), PMA-triggered chemiluminescence was sharply elevated around $2 \mathrm{~d}$ p.i. and rapidly declined thereafter (Fig. $4 b$ ). Marked enhancement of phagocytosis-associated chemiluminescence was also noted around $2 \mathrm{~d}$ p.i. In this case, the PC of mice from 1 to $4 \mathrm{~d}$ p.i. contained a high proportion of PMNL (Fig. 4f), which probably contributed considerably to the elevated chemiluminescence seen around $2 \mathrm{~d}$ p.i.

Fig. 5 shows the changes in macrophage $\mathrm{H}_{2} \mathrm{O}_{2}$-releasing ability during sublethal and lethal $L$. monocytogenes infection. The $\mathrm{H}_{2} \mathrm{O}_{2}$ release in response to $100 \mathrm{ng}$ PMA ml-1 markedly increased even $1 \mathrm{~d}$ p.i., regardless of the infecting dose, and remained high until elimination of the infection (Fig. $5 a$ ) or the death of the animals (Fig. $5 b$ ). Since the PC preparation at $1 \mathrm{~d}$ p.i. contained a high proportion of PMNL (Fig. 4) and the macrophage monolayer was thus highly contaminated with PMNL (Fig. $5 c, d$ ), the $\mathrm{H}_{2} \mathrm{O}_{2}$ release at $1 \mathrm{~d}$ p.i. may have been partly generated by PMNL. 

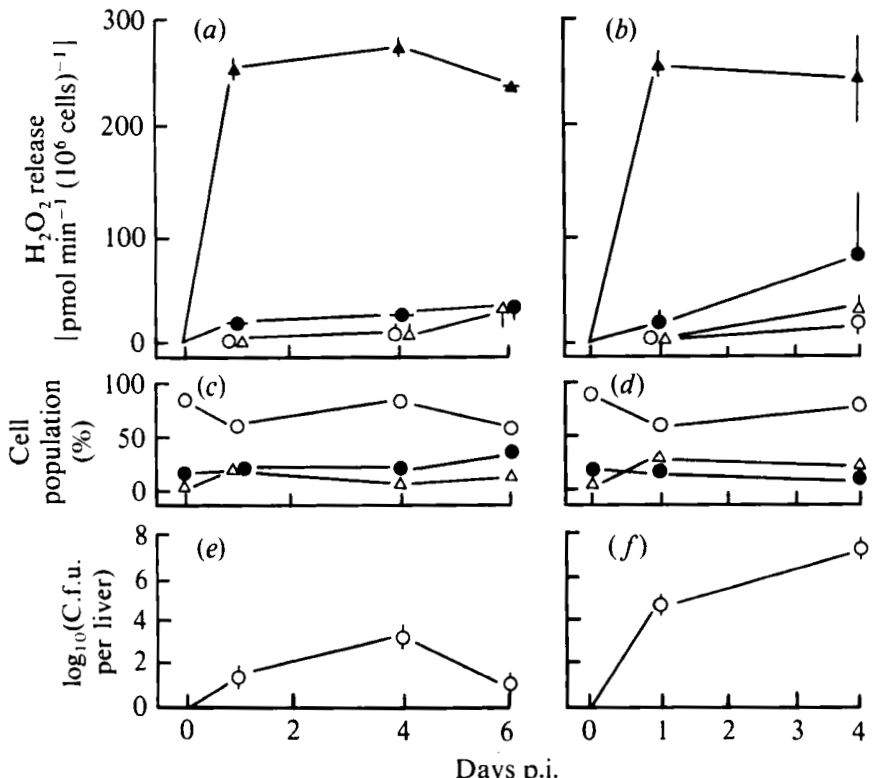

Fig. 5. Changes in PMA-triggered $\mathrm{H}_{2} \mathrm{O}_{2}$ release from host macrophages after intraperitoneal infection with $L$. monocytogenes at doses of $1.5 \times 10^{6}$ (sublethal) $(a, c, e)$ and $2.5 \times 10^{7}$ (lethal) $(b, d, f)$ organisms per mouse. $(a, b) \mathrm{H}_{2} \mathrm{O}_{2}$ release; $(c, d)$ cell population in the macrophage monolayer culture tested: $\mathrm{O}$, macrophages: $\triangle$, PMNL: , lymphocytes; $(e, f)$ number of c.f.u. of organisms in the liver. In the lethal infection, 60 and $0 \%$ of the mice survived at 4 and $6 \mathrm{~d}$ p.i., respectively. See Fig. 3 for other details.
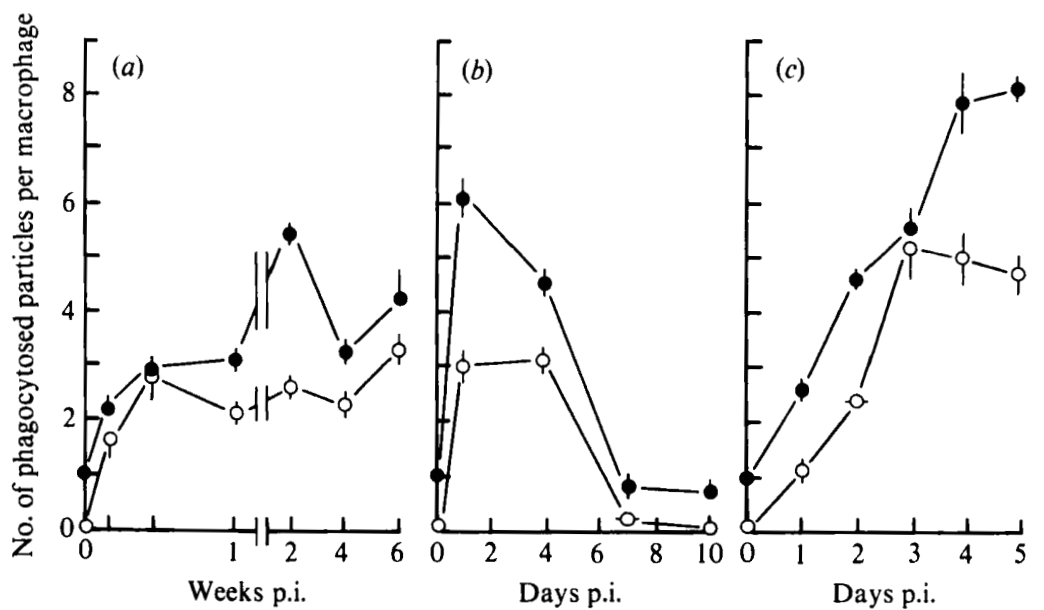

Fig. 6. Changes in macrophage phagocytic activity against latex beads in the presence ( $)$ or absence $(\mathrm{O})$ of $10 \mathrm{ng}$ PMA ml-1 after infection due to $M$. intracellulare $(a)$ and $L$. monocytogenes at sublethal $(b)$ or lethal $(c)$ doses. The macrophages were harvested from the animals tested in the experiments shown in Figs 1 and 4.

Changes in the phagocytic ability of host macrophages against latex particles after infection with $M$. intracellulare or L. monocytogenes

In $M$. intracellulare infection (Fig. $6 a$ ), macrophage phagocytic activity against latex beads was markedly enhanced even $1 \mathrm{~d}$ p.i. and gradually increased thereafter. The addition of $10 \mathrm{ng}$ PMA ml-1 to the phagocyosis incubation medium led to a slight $(1 \cdot 1-$ to 2 -fold) increase in the phagocytic activity of the host macrophages. It is noteworthy that the phagocytic capacity of non-infected macrophages (resident peritoneal macrophages) was markedly enhanced by PMA. 
In the listerial infections (Fig. $6 b, c$ ), the phagocytic patterns in the macrophage differed markedly, depending on the infection dose. In the case of sublethal infection, macrophage phagocytic activity in the absence of PMA was markedly increased at $1 \mathrm{~d}$ p.i., remained elevated until $4 \mathrm{~d}$ p.i. and then rapidly decreased (Fig. $6 \mathrm{~b}$ ). The pattern was similar in the presence of PMA, but with a sharp peak at $1 \mathrm{~d}$ p.i., when the enhancement by PMA was most marked. In contrast, in the case of lethal infection (Fig. $6 c$ ), the onset of enhanced phagocytic activity of the host macrophages was somewhat slower (with or without PMA). In the absence of PMA, phagocytic aotivity reached a maximum $3 \mathrm{~d}$ p.i., which was retained until the death of the animals. With PMA, phagocytic activity continued to increase until the death of the animals.

\section{DISCUSSION}

In $M$. intracellulare infection, PMA-triggered chemiluminescence of macrophages rapidly decreased between the second and sixth week, whereas the PMA-elicited $\mathrm{H}_{2} \mathrm{O}_{2}$ release was retained at a high level for 10 weeks. Similar differences were noted in the patterns of the alterations of chemiluminescence and $\mathrm{H}_{2} \mathrm{O}_{2}$-releasing ability of the host macrophages during $L$. monocytogenes infection, regardless of the infection dose. If macrophage chemiluminescence originates from ${ }^{1} \mathrm{O}_{2}$ or ${ }^{\circ} \mathrm{OH}$ (Cheson et al., 1976; Miles et al., 1978) rather than $\mathrm{O}_{2}^{-}$, the discrepancy between the patterns of change in PMA-triggered chemiluminescence and $\overline{\mathrm{H}}_{2} \mathrm{O}_{2}$ release is not so enigmatic. In macrophages, ${ }^{1} \mathrm{O}_{2}$ or ${ }^{\circ} \mathrm{OH}$ are generated mainly through the Harber-Weiss reaction, catalysed by iron and tryptophan (Halliwell, 1978; Fong et al., 1978), from $\mathrm{O}_{2}^{-}$and $\mathrm{H}_{2} \mathrm{O}_{2}$, and this reaction is thought to be regulated by a different cellular mechanism from that related to regulation of PMA-triggering of NADPH oxidase, conversion of $\mathrm{O}_{2}{ }^{-}$to $\mathrm{H}_{2} \mathrm{O}_{2}$, and the $\mathrm{H}_{2} \mathrm{O}_{2}$-releasing process itself. In macrophages of mice infected with $M$. intracellulare, the Harber-Weiss reaction step was probably most accelerated at 2 weeks p.i., following a 1 week lag, although the PMA-triggered oxidative burst was enhanced even $1 \mathrm{~d}$ after infection and a high level of activity was retained thereafter. This may explain differences between the patterns of change in the chemiluminescence and $\mathrm{H}_{2} \mathrm{O}_{2}$ release after infection.

As reported by Nathan \& Root (1977) and by our group (Tomioka \& Saito, 1980; Saito et al., 1981), the PMA responsiveness of a given macrophage cell correlates well with its stimulated and/or activated state. That is, immunologically activated macrophages show a higher responsiveness to PMA-triggering for $\mathrm{H}_{2} \mathrm{O}_{2}$ and $\mathrm{O}_{2}{ }^{-}$release than do chemically stimulated macrophages (Tomioka \& Saito, 1980; Johnston et al., 1978) and resident macrophages lack such a responsiveness (Nathan \& Root, 1977; Saito et al., 1981). Therefore, host macrophages are thought to be stimulated and/or activated during infections due to $M$. intracellulare and $L$. monocytogenes. It is noteworthy that the responsiveness of macrophage to PMA at $100 \mathrm{ng} \mathrm{ml}^{-1}$ was markedly elevated as early as $1 \mathrm{~d}$ after bacterial challenge, in both infections, although a considerable part of the apparent $\mathrm{H}_{2} \mathrm{O}_{2}$ release from the macrophage culture may have originated from contaminating PMNL because PMNL produce amounts of $\mathrm{H}_{2} \mathrm{O}_{2}$ similar to activated macrophages (Nathan \& Root, 1977). Since the T-cell mediated immune response to the infected organisms had barely developed at this stage, the increase in PMA-responsiveness of the host macrophages is more likely to have been due to a direct stimulation or activation of their cell functions by contact with component(s) or product(s) of the infecting bacteria or mediator(s) derived from the inflammatory process (Pabst \& Johnston, 1980; Diaz et al., 1979). Host macrophages from animals infected with $M$. intracellulare could respond to $10 \mathrm{ng}$ PMA $\mathrm{ml}^{-1}$, whereas the macrophages of mice with $L$. monocytogenes infection did not respond to this dose of PMA (Figs 3 and 5). Thus the degree of stimulation (or activation) of the host macrophages in the former infection is evidently much higher than that in the latter. In separate experiments, macrophages induced by a single intraperitoneal injection of thioglycollate or Zymosan A $4 \mathrm{~d}$ before harvesting showed a significant chemiluminescent response to PMA, but it was much lower (thioglycollate-induced macrophages, $3.2,5.8$ and $7.6 \times 10^{3}$ c.p.m. per $10^{6}$ cells; Zymosan A-induced macrophages, 3.1,6.4 and 5.9 $\times 10^{4}$ c.p.m. per $10^{6}$ at 1,10 and $100 \mathrm{ng}$ PMA ml-1, respectively) than that of macrophages of mice 2 weeks after $M$. intracellulare infection ( 1.9 to $3.4 \times 10^{5}$ c.p.m. per $10^{6}$ cells $)$. The macrophages at this stage of $M$. intracellulare 
infection thus seem to have a higher ability for producing an oxidative burst than do chemically elicited macrophages. Furthermore, macrophage $\mathrm{H}_{2} \mathrm{O}_{2}$-releasing ability without triggering by PMA or in response to a low concentration of PMA $\left(1 \mathrm{ng} \mathrm{ml}^{-1}\right)$ increased at around the same stage of the infection. These findings suggest the generation of immunologically activated macrophages which are highly responsive to PMA (Tomioka \& Saito, 1980). Generation of activated macrophages is evident in infections with other mycobacteria, such as $M$. tuberculosis (North, 1974) and M. bovis (Mackaness, 1969). The possibility that an increase in the number or affinity of PMA receptors during the infections caused the increase in the PMA responsiveness of the host macrophages may be excluded, since there is evidence that in vivo 'activation' of macrophages in mice infected with BCG is not associated with a change in the cell's receptors for phorbol diesters (Weinberg \& Misukonis, 1983). As they proposed, the increase in PMA responsiveness for an oxidative burst in the host macrophages may be associated with 'postreceptor' changes such as the induction of the synthesis of NADPH oxidase, an increase in the affinity of the enzyme for its substrate, or 'linking' of the NADPH oxidase system with the phorbol diester receptor.

Campbell and his colleagues (Czuprynski et al., 1983, 1984) proposed that, in a $L$. monocytogenes infection, monocytes and PMNL, but not monocyte-derived 'activated' macrophages, play a central role in the resistance of the host to the parasites. They demonstrated that increased mobilization of PMNL and mononuclear phagocytes into the site of infection is of prime importance in resistance to listeriosis (Czuprynski et al., 1984). This is consistent with our findings in sublethal L. monocytogenes infections, in which chemiluminescence of host macrophages was less elevated than in lethal infections (Fig. $4 a$ ), and that the host macrophages did not acquire responsiveness to a low dose of PMA during the course of L. monocytogenes infection until the infecting organism had been eliminated (Fig. $5 a$ ).

Macrophage phagocytic ability was markedly enhanced even $1 \mathrm{~d}$ p.i. in both experimental infections, indicating a rapid stimulation of macrophage cell function, presumably due to acute inflammation. In $M$. intracellulare infection (chronic infection), the enhanced state persisted for up to 6 weeks. This is consistent with the change seen in PMA-triggered $\mathrm{H}_{2} \mathrm{O}_{2}$-releasing ability of the macrophages. On the other hand, in case of $L$. monocytogenes infection at a sublethal dose, the enhanced state rapidly declined, almost in parallel with the elimination of the organisms (Figs 4 and 6). Differing from $M$. intracellulare infection, this pattern resembled that of PMAtriggered chemiluminescence of the host macrophages infected with L. monocytogenes. This indicates essential differences between changes in macrophage cell functions during the chronic and acute infections, with sublethal doses. Interestingly, in L. monocytogenes infection induced by a lethal dose (acute infection), the phagocytic ability of the host macrophages increased almost continuously until the death of the animals.

Our study has revealed that two macrophage functions related to oxidative burst, namely chemiluminescence and $\mathrm{H}_{2} \mathrm{O}_{2}$ release, can be differentiated on the basis of their patterns of changes after $M$. intracellulare and $L$. monocytogenes infections. It is important to know which function relates to the activated or suppressed state of the host macrophages during infection, because, at present, both functions are used as measures of macrophage activation.

We thank M. Ohara for comments on the manuscript.

\section{REFERENCES}

Brummer, E., Morozumi, P. A. \& Stevens, D. A. (1980). Macrophages and fungi: in vitro effects of method of macrophage induction, activation by different stimuli, and soluble factors on Blastomyces. Journal of the Reticuloendothelial Society 28, 507518.

Campbell, P. B. (1979). Defective leukotaxis in monocytes from patients with pulmonary tuberculosis. Journal of Infectious Diseases 139, 409-417.

Cheers, C. \& Pagram, F. (1979). Macrophage activation during experimental murine brucellosis : a basis for chronic infection. Infection and Immunity 23, 197-205

Cheson, B. D., Christensen, R. L., Sperling, R., KOHLER, B. E. \& BABIOR, B. M. (1976). The origin of the chemiluminescence of phagocytosing granulocytes. Journal of Clinical Intestigation 58, 789-796.

Czuprynski, C. J., Campbell, P. A. \& Henson, P. M. (1983). Killing of Listeria monocytogenes by human neutrophils and monocytes, but not by monocytederived macrophages. Journal of the Reticuloendothelial Society 34, 29-44. 
Czupr ynski, C. J., Henson, P. M. \& Campbell, P. A. (1984). Killing of Listeria monocytogenes by inflammatory neutrophils and mononuclear phagocytes from immune and nonimmune mice. Journal of Leukocyte Biology 35, 193-208.

Diaz, P., Jones, D. G. \& KaY, A. B. (1979). Histamine-coated particles generate superoxide $\left(\mathrm{O}_{2}^{-}\right)$and chemiluminescence in alveolar macrophages. Nature, London 278, 454-456.

Fong, K.-L., MCCAY, P. B. \& Poyer, J. L. (1978). Evidence for superoxide-dependent reduction of $\mathrm{Fe}^{3+}$ and its role in enzyme-generated hydroxyl radical formation. Chemical-Biological Interactions 15, 77-89.

Halliwell, B. (1978). Superoxide-dependent formation of hydroxyl radicals in the presence of iron chelates. FEBS Letters 92, 321-326.

JoHNSTON, R. B., JR (1978). Oxygen metabolism and microbicidal activity of macrophages. Federation Proceedings 37, 2759-2764.

Johnston, R. B., JR, Godzik, C. A. \& Cohn, Z. A. (1978). Increased superoxide anion production by immunologically activated and chemically elicited macrophages. Journal of Experimental Medicine 148, 115-127.

Jones, T. \& LEN, L. (1976). Pinocytic rates of macrophages from mice immunized against Toxoplasma gondii and macrophages stimulated to inhibit toxoplasma in vitro. Infection and Immunity 14, 10111013.

King, G. W., Bain, G. \& LoBuglio, A. F. (1975). The effect of tuberculosis and neoplasia on human monocyte staphylocidal activity. Cellular Immuno$\log y$ 16, 389-395.

MACKANESS, G. B. (1969). The influence of immunologically committed lymphoid cells on macrophage activity in vivo. Journal of Experimental Medicine 129, 973-992.
Miles, P. R., Castranova, V. \& Lee, P. (1978). Reactive forms of oxygen and chemiluminescence in phagocytizing rabbit alveolar macrophages. American Journal of Physiology 253, C103-C108.

Nathan, C. F. \& Root, R. K. (1977). Hydrogen peroxide release from mouse peritoneal macrophages. Dependence on sequential activation and triggering. Journal of Experimental Medicine 146, 1648-1662.

Nogueira, N., Gordon, S. \& Cohn, Z. A. (1977). Trypanosoma cruzi: modification of macrophage function during infection. Journal of Experimental Medicine 146, 157-171.

NORTH, R. J. (1974). T cell dependence of macrophage activation and mobilization during infection with Mycobacterium tuberculosis. Infection and Immunity 10, 66-71.

PABst, M. J. \& Johnston, R. B., JR (1980). Increased production of superoxide anion by macrophages exposed in vitro to muramyl dipeptide or lipopolysaccharide. Journal of Experimental Medicine 151, 101114.

SaIto, H., Tomioka, H. \& Watanabe, T. (1981). $\mathrm{H}_{2} \mathrm{O}_{2}$ releasing function of macrophages activated with various mycobacteria based on wheat germ agglutinin and phorbol myristate acetate triggering. Journal of the Reticuloendothelial Society 29, 193-204.

TOMIOKA, H. \& SAITO, H. (1980). Hydrogen peroxidereleasing function of chemically elicited and immunologically activated macrophages: differential response to wheat germ lectin and concanavalin A. Infection and Immunity 29, 469-476.

Weinberg, J. B. \& Misuxonis, M. A. (1983). Phorbol diester-induced $\mathrm{H}_{2} \mathrm{O}_{2}$ production by peritoneal macrophages. Cellular Immunology 80, 405-415.

WING, E. J. (1981). Bacillus Calmette-Guérin (BCG) decreases resistance to Listeria monocytogenes infection in mice. Immunology 44, 509-515. 